\title{
Achieving negative emissions through oceanic sequestration of vegetation carbon as Black Pellets
}

\author{
Leonard A. Miller ${ }^{1}$ (D) Philip M. Orton ${ }^{2}$ (iD \\ Received: 17 March 2020 / Accepted: 9 July 2021/ Published online: 3 August 2021 \\ (C) The Author(s) 2021, corrected publication 2021
}

\begin{abstract}
Natural processes and human activities produce vast amounts of dead vegetation which return $\mathrm{CO}_{2}$ to the atmosphere through decay and combustion. If such vegetation could be converted into biocoal and sequestered on the ocean floor, it could reduce the accumulation of atmospheric $\mathrm{CO}_{2}$ without involving sequestration in the form of $\mathrm{CO}_{2}$. Given that raw vegetation is unsuitable for large-scale energy applications, a process was developed to convert raw vegetation into a form of biocoal, termed Black Pellets, that solves the logistical and energy conversion problems of using raw vegetation for power generation. Seemingly overlooked is that properties of Black Pellets-higher density than seawater and resistance to microbial decay-may offer an environmentally safe way of sequestering vegetation carbon on the sea floor. Sequestering vegetation carbon by depositing biocoal as Black Pellets in the deep ocean (oceanic sequestration of biocoal-OSB) would be a means of achieving long-lasting negative emissions. Sacrificing the energy content of the deposited pellets would require substituting energy from other sources. If the substitute energy could be from lower-carbon natural gas or carbon-free sources, the effects would be less accumulation of atmospheric $\mathrm{CO}_{2}$ compared to using the pellets for energy and a nearly 60 to $100 \%$ reduction in the need for geologic sequestration compared to bioenergy carbon capture and storage (BECCS). If confirmed by research, OSB would be an addition to the sparse toolbox of negative emission technologies (NETs) which would give humankind more flexibility in meeting the goals of the Paris Agreement.
\end{abstract}

Keywords Climate change - Negative emissions · Oceanic sequestration · Biocoal · Black Pellets · Torrefaction

Leonard A. Miller

leonard.miller@alumni.stevens.edu

1 visiting researcher, Stevens Institute of Technology, Hoboken, NJ, USA

2 Oceanography Department, Stevens Institute of Technology, Hoboken, NJ, USA 


\section{Introduction}

\subsection{Properties of Black Pellets and their existing use in generating useful energy}

Raw vegetation has properties that make it unsuitable for large-scale energy applications. Its low energy density and high moisture content make it inefficient for generating useful energy. Its high moisture content leads to decomposition and greenhouse gas emissions which, coupled with its irregular shapes and low bulk density, make the storage and transportation of raw vegetation problematic.

A process was invented by the Energy Research Centre of the Netherlands (the TOP process) to transform vegetation biomass into a form that solves the logistical and useful energy production problems of raw plant material (Bergman 2005). It involves the near autothermal torrefaction (mild pyrolysis) of raw biomass to produce a brittle char-like substance that preserves a high percentage of the feedstock's carbon content. The material is subsequently densified into biocoal pellets (Black Pellets) with properties that are favorable to their transportation and use for energy applications, namely: these pellets have a higher energy density than raw vegetation, a greater bulk density, homogeneous shapes and content, durability, water resistance, and resistance to microbial degradation.

Black Pellets are commercially available and are produced in accordance with chemical and physical property standards promulgated to enable the efficient trading of solid biofuels that meet environmental sustainability criteria for industrial energy applications such as power generation. The term black pellets also pertains to those pellets produced through steam explosion technology, a less commercially advanced process. For the purposes of this paper, "Black Pellets" is taken to mean torrefied black pellets.

\subsection{Proposed new use of Black Pellets to produce negative emissions}

Particular chemical and physical properties of Black Pellets appear to make the pellets uniquely suited for sequestering vegetation carbon on the ocean floor. As Black Pellets are denser than seawater, they will sink on their own. Subject to research and design, their durability to maintain their integrity through transportation and descent to the sea floor, their resistance to microbial decay, and their lack of harmful chemicals mean Black Pellets offer the potential of long-lasting sequestration of vegetation carbon with acceptable effects on the ocean's condition and its biota.

It is useful to think of Black Pellets made from dead vegetation as being a form of sequestered $\mathrm{CO}_{2}$ that otherwise would be released in the atmosphere through decay or open fires if the pellets were not created. Figuratively, Black Pellets are "packets of concentrated negative emissions." If the pellet material is deposited in the very deep ocean, it would offer the possibility of millennial sequestration of the $\mathrm{CO}_{2}$-equivalent that is locked up in the pellets.

Additionally, purpose-grown short-rotation woody and herbaceous crops harvested from "energy plantations" have been studied for their potential to be environmentally beneficial feedstocks for energy applications. Coppicing is a method of periodically obtaining biomass from certain fast-growing trees and other species by cutting them back to their stumps from which they regrow. If harvested for producing Black Pellets for oceanic deposition, such areas of short-rotation cultivation would become "negative emissions plantations." 


\subsection{Purposes of this paper}

This paper has three purposes: (1) to introduce the concept and effects of oceanic deposition of Black Pellets, (2) to address the question of whether it is better to burn the Black Pellets for their energy content or to use the pellets for their negative emissions value by depositing them in the sea, and (3) to initiate discourse and spawn research that would be required for technical, legal, and social acceptance of OSB as an ocean-based NET.

This paper adopts as a given - its baseline - that there will be some unknown quantity of Black Pellets produced in the future that meet environmental sustainability criteria and that will be used first as a near-zero-emissions power source and, subsequently, with carbon capture and geologic storage (CCS) of power plant stack emissions, a negative emissions means of generating power (BECCS). Considering that many integrated assessment model (IAM) scenarios envision a meaningful role for BECCS to meet the Paris Agreement goals (National Academies of Sciences, Engineering, and Medicine 2019, pg. 137) and that Black Pellets are widely regarded as a promising means of enabling vegetation feedstocks to be used to generate power (Batidzirai et al. 2016), the baseline assumption of this paper is implicitly a common feature of many scenarios for mitigating climate change.

Given that global demand for power should be the same whether the pellets are deposited in the ocean or used in power plants, a comparison of OSB on an equal footing to the baseline case in which the pellets are used for power requires that energy for power generation from other sources be substituted for the sacrificed energy content of Black Pellets deposited in the sea. The conjecture investigated in this paper is that if the source of the substitute energy has a lower-carbon content than that of the Black Pellets or is carbon free, the combination of the negative emissions achieved by depositing the pellets in the ocean plus the lower positive emissions associated with generating power with the substitute energy source would result in less $\mathrm{CO}_{2}$ in the atmosphere than if the Black Pellets were burned for power after all life cycle emissions are taken into account. This conjecture is analyzed for three forms of substitute energy: coal, natural gas, and a carbon-free source (photovoltaic solar), with and without the availability of geologic storage of power plant stack emissions (CCS).

\subsection{Scope of this paper}

This paper is limited to the question of whether it is better to use Black Pellets for their energy value to generate power or for their direct negative emissions value by depositing them in the ocean ("bury-versus-burn" decision). As the scope of this paper is limited to a comparison of the use of the same Black Pellets for power or for oceanic deposition, it excludes issues that equally affect both alternatives. For example, the sustainability of particular vegetation feedstocks; alternative uses of dead vegetation for ecological, agricultural, or heating purposes; land use competition with agriculture; and biodiversity preservation all represent limitations on the potential amount of environmentally beneficial vegetation biomass the world could produce for conversion to Black Pellets; however, as these limitations are common to both OSB and the use of the pellets for power generation, they are issues that fall outside the scope of this paper. Also outside the scope of this paper are limitations on the availability of Black Pellets for OSB or power generation due to competition from the use of vegetation feedstocks to produce transportation fuels and chemicals through pyrolysis or gasification.

Another competing use of vegetation feedstocks would be to produce biochar to be used for achieving negative emissions through soil sequestration. Why deposit the biocoal in the ocean 
for negative emissions when negative emissions can be achieved by using the same vegetation feedstocks to make biochar for sequestration on land in soils with agricultural benefits? As an alternative use of vegetation feedstocks, this question is also outside the scope of this paper. Extensive literature exists about soil sequestration of biochar and unsettled issues about its usefulness such as logistics, global applicability, and sequestration persistence have been raised (Tisserant and Cherubini 2019) that would make a comparison to OSB to be lengthy but inconclusive. More importantly, OSB and soil sequestration of biochar are not mutually exclusive NETs. Geographically and over time, circumstances could arise that favor each alternative. The key point as stated in the National Academies of Sciences, Engineering, and Medicine (2019, pg. 2) report on negative emissions is that having a portfolio of technologies that includes multiple NETs would be the least disruptive, least risky way of addressing the climate change problem. "The Earth needs multiple methods for removing $\mathrm{CO}_{2}$ from the air to avert the worst of climate change....all possibilities for carbon capture and storage need to be pursued in parallel" (Goldberg 2019). Accordingly, at this stage of knowledge, the purpose of this paper is simply to initiate discourse and suggest research with the objective of adding OSB to the sparse toolbox of NETs to provide more flexibility in planning the fight against climate change.

OSB is a multifaceted concept that includes feedstock sourcing, thermochemical processing and pellet production, supply chains and global logistics, power generation and emissions effects, oceanic capacity and environmental consequences, and sociological, economics, governance, and legal considerations. Each of these topics is potentially vast and their exhaustive coverage here would not be possible. Practicalities constrain this paper to a presentation of the novel central points of OSB and to the suggestion of an initial research agenda for answering threshold viability questions about the concept.

\section{Life cycle analysis of OSB}

Here, OSB is analyzed in absolute terms, without "substitute energy" considerations. A representative cradle-to-grave life cycle assessment (LCA) is presented based on data from the literature of the net emissions effects of depositing vegetation carbon on the sea floor as Black Pellet material.

\subsection{Methods}

The net emissions effect of OSB is computed as the negative emissions of the $\mathrm{CO}_{2}$-equivalent $\left(\mathrm{CO}_{2 \mathrm{e}}\right)$ of the carbon contained in the pellet material on the sea floor (direct emissions effect) minus the positive emissions from all pellet supply chain stages including feedstock sourcing, pellet production, and transportation to their seafloor destination (indirect emissions effects).

The $\mathrm{CO}_{2 \mathrm{e}}$ of pellet material on the sea floor is computed from measurements of the carbon contents of torrefied pellets taken from a literature review by Hasan et al. (2018). This review provided a compilation of 152 measurements from many sources of the ultimate analysis of the carbon contents and heating values of pellets representing 15 different types of wood feedstocks under 43 different torrefaction conditions. Supply chain studies from the literature regarding emissions from the production of Black Pellets and their usage for generating power are adapted for a seafloor destination. Supply chain emissions estimates are taken from a search by Martin-Gamboa et al. (2020) of peer-reviewed journals published from 2009 to 2019 that meet the search criteria of "life-cycle assessment," "pellet," and "biomass." 


\subsection{Analysis of the $\mathrm{CO}_{2 \mathrm{e}}$ negative emissions content of Black Pellets}

The carbon contents of the 152 pellet samples reported in Hasan et al. (2018) ranged from 47.1 to 64.4 weight percent and were clustered around $55 \%$ on a moisture and ash-free basis, or approximately $52 \%$ when allowing for their moisture and ash contents. The higher heating values (HHVs) of these samples ranged from 16.6 to $26.9 \mathrm{MJ} / \mathrm{kg}$ and were clustered around 22 $\mathrm{MJ} / \mathrm{kg}$. These values of $52 \%$ carbon content and $22 \mathrm{MJ} / \mathrm{kg} \mathrm{HHV}$ are used in this paper. These values may be conservative with what would be a selection bias in favor of using the bestyielding feedstocks and the likelihood of improvements in torrefaction technology over time.

With carbon dioxide weighing 3.667 times the weight of its constituent carbon, a tonne of pellets deposited on the sea floor having $52 \%$ carbon would be the equivalent of 1.91 tonnes of negative $\mathrm{CO}_{2}$ emissions. From this must be subtracted the positive emissions from the supply chain of feedstock sourcing, pellet production, and their seafloor delivery.

\subsection{Supply chain emissions delivering Black Pellets to power plant and seafloor destinations}

\subsubsection{Cradle-to-gate supply chain emissions from delivering Black Pellets to power plants}

The literature review of pellet supply chain emissions by Martin-Gamboa et al. (2020) resulted in 84 usable articles covering multiple scenarios with great variations regarding types of feedstocks and their geographic origins and destinations; energy sources and requirements, particularly for pretreatment feedstock drying; pellet types (pelletized raw wood "White Pellets" and torrefied Black Pellets); methodological approaches; and scopes of study (cradle-to-grave or cradle-to-gate).

After attempting to harmonize these highly diverse studies of pellet supply chain emissions to a common analytical basis, $60 \%$ of the results from 149 cradle-to-gate scenarios had supply chain emissions below $25 \mathrm{gCO}_{2 \mathrm{e}}$ per MJ energy content of the pellets (Martin-Gamboa et al. 2020). Scenarios that fell above this level were, in part, attributable to the relatively low energy densities of White Pellets. The higher energy densities of Black Pellets would place them in the range of supply chain emissions below $25 \mathrm{gCO}_{2 \mathrm{e}} / \mathrm{MJ}$, with all other factors constant. This is consistent with several individual studies that have been examined. For example, in a cradleto-gate study of torrefied wood pellets transported from Norway to a power plant in England, Adams et al. (2015) reported a base case result of $17.5 \mathrm{gCO}_{2 \mathrm{e}} / \mathrm{MJ}$ total supply chain emissions, and for an alternative scenario regarding pellets transported from Canada, the result was 18.5 $\mathrm{gCO}_{2 \mathrm{e}} / \mathrm{MJ}$. Similarly, in a cradle-to-gate study of a representative case of torrefied wood pellets transported from Mississippi to a power plant in England, McNamee et al. (2016) reported $17.2 \mathrm{gCO}_{2 \mathrm{e}} / \mathrm{MJ}$ supply chain emissions. For the purposes herein, $17.5 \mathrm{CO}_{2 \mathrm{e}} / \mathrm{MJ}$ is selected as a representative value of total cradle-to-gate supply chain emissions of Black Pellets where their destination is an overseas power plant. This value converts to approximately 0.39 tonnes $\mathrm{CO}_{2 \mathrm{e}}$ per tonne of $22 \mathrm{MJ} / \mathrm{kg}$ Black Pellets.

\subsubsection{Cradle-to-gate supply chain emissions delivering Black Pellets to seafloor sites}

How might the unique transportation destination of OSB affect the foregoing supply chain results that were obtained based on the overseas delivery of pellets to a power plant somewhere on land? Several supply chain studies of the use of Black Pellets for overseas power generation 
broke out transportation-to-destination emissions. In the study by Adams et al. (2015), road and seaborne transportation-to-destination of $1346 \mathrm{~km}$ from Norway to England contributed $3.0 \mathrm{gCO}_{2 \mathrm{e}} / \mathrm{MJ}$ to the total supply chain emissions while this value was approximately 4.0 $\mathrm{gCO}_{2 \mathrm{e}} / \mathrm{MJ}$ for a scenario of transportation distance of $6510 \mathrm{~km}$ for pellets originating in Canada. In the McNamee et al. (2016) study, transporting pellets from Mississippi $8912 \mathrm{~km}$ by sea and $51 \mathrm{~km}$ by road to a power plant in England contributed approximately $5.6 \mathrm{gCO}_{2 \mathrm{e}} /$ $\mathrm{MJ}$ of the total supply chain emissions. In a study of torrefied wood pellets from Mississippi to Rotterdam, Thrän et al. (2016) estimated emissions of $4.2 \mathrm{gCO}_{2 \mathrm{e}} / \mathrm{MJ}$ for transporting pellets to their destination. For the purposes herein, $4.0 \mathrm{gCO}_{2 \mathrm{e}} / \mathrm{MJ}$ is taken as the global average of emissions from medium- to long-distance transportation-to-destination of Black Pellets where their destination is an overseas power plant. This converts to an estimated global average of 0.09 tonnes of $\mathrm{CO}_{2 \mathrm{e}}$ emissions from transporting a tonne of $22 \mathrm{MJ} / \mathrm{kg}$ Black Pellets from their production plant to some overseas power plant.

Studies of the potential markets and trades of Black Pellets have envisioned a large-scale international movement of Black Pellets in bulk tankers, much of which is produced in remote areas of forests and agricultural activities in less developed parts of the world and shipped overseas to power plants in areas of population concentrations (Wild et al. 2016). Instead, where the end-use of the pellets would be deposition in internationally approved ocean sites, this may involve relatively short-haul shipping. Without an inland destination, OSB would also entail less land transportation. Therefore, it can reasonably be assumed that, on average, less seaborne and land transport of pellets would be needed for oceanic deposition and transportation considerations would mean less overall supply chain emissions than delivering the pellets to overseas power plants. Everything considered, a representative emissions estimate for the transportation-to-destination supply chain stage for pellets to an ocean deposition site is taken to be $80 \%$ of the emissions estimate for the transportation stage of delivering pellets to an overseas power plant, or approximately 0.07 tonnes $\mathrm{CO}_{2 \mathrm{e}}$ per tonne of pellets. Thus, a representative estimate of the total supply chain emissions for Black Pellets to an ocean destination becomes 0.37 tonnes $\mathrm{CO}_{2 \mathrm{e}}$ per tonne of pellets compared to the 0.39 tonnes $\mathrm{CO}_{2 \mathrm{e}}$ per tonne of pellets supply chain total emissions where the destination is an overseas power plant.

\subsection{Results-OSB life cycle assessment}

The foregoing LCA results in a net negative emissions of 1.54 tonnes of $\mathrm{CO}_{2 \mathrm{e}}$ per tonne of Black Pellet material on the sea floor, that is, the sum of 1.91 tonnes of direct negative $\mathrm{CO}_{2 \mathrm{e}}$ emissions in a tonne of pellet material on the sea floor plus 0.37 tonnes of indirect $\mathrm{CO}_{2 \mathrm{e}}$ positive emissions from the supply chain of producing the pellets and delivering them to the sea floor.

\section{Black Pellet "bury-versus-burn" comparisons with various sources of substitute energy, with and without CCS}

Here, using Black Pellets to achieve negative emissions through OSB is analyzed in relative terms, that is, it is investigated whether it is better, from a net emissions standpoint, to bury or burn the pellets. In this analysis, "burn" indicates two baseline scenarios in which Black Pellets are used for their "conventional" purpose of producing electricity in direct-fired power plants, 
namely: (1) first, the Black Pellets are burned as an (almost) net-zero-emissions power source, and then (2) the pellets are burned to produce power and negative emissions in a BECCS configuration. In these comparisons "bury" indicates alternative scenarios in which the pellets are deposited in the ocean (OSB) and the power that could have been generated by the sacrificed energy in the pellet material on the sea floor is replaced with power generated by substitute forms of energy. The following "bury-versus-burn" comparisons based on assumed chronological alternative substitute energy scenarios (successive phases of the decarbonization of the world's power generation) are analyzed for their net emissions and geologic sequestration effects:

- Phase 1-OSB plus substitute energy from coal versus the baseline scenario in which Black Pellets are burned for power without CCS.

- Phase 2-OSB plus substitute energy from natural gas versus the baseline scenario in which Black Pellets are burned for power without CCS.

- Phase 3-OSB plus substitute energy from natural gas with CCS (fossil fuel CCS) versus the baseline scenario in which Black Pellets are burned for power with CCS (BECCS).

- Phase 4 -OSB plus substitute energy from photovoltaic solar versus the baseline scenario in which Black Pellets are burned for power with CCS.

\subsection{Methods}

For the baseline case of burning the pellets for power without CCS, its direct emissions effect is taken to be net zero, with the combustion of the pellets producing $\mathrm{CO}_{2}$ emissions to the atmosphere that are equal to the $\mathrm{CO}_{2}$ that was removed from the atmosphere through photosynthesis by the pellets' vegetation feedstocks. The total indirect supply chain emissions for a tonne of Black Pellets delivered to a power plant was computed to be 0.39 tonnes $\mathrm{CO}_{2 \mathrm{e}}$ from a literature search on pellet life cycle assessments by Martin-Gamboa et al. (2020) and other sources as described in "Section 2.3.1."

For OSB, the direct negative emissions of a tonne of pellets on the sea floor were computed as 1.91 tonnes $\mathrm{CO}_{2 \mathrm{e}}$ in "Section 2.2." The indirect supply chain emissions to produce and deliver a tonne of pellets to the sea floor were taken as 0.37 tonnes $\mathrm{CO}_{2 \mathrm{e}}$ from the supply chain results in "Section 2.3.2" as adapted for a seafloor destination.

The direct and indirect emissions effects resulting from generating an amount of substitute power that is equal to what would be produced by burning a tonne of Black Pellets were calculated based on median data for direct-fired pulverized coal, natural gas combined cycle, and photovoltaic solar power production technologies from a literature review by Schlömer (2014).

Geologic sequestration of power plant stack emissions (CCS) is introduced in the Phase 3 bury-versus-burn comparison. The results of OSB plus substitute energy from natural gas with CCS are compared against the baseline scenario in which Black Pellets are used for power generation in a BECCS configuration. The effects of CCS on useful power generation and on net negative emissions are developed from data taken from Metz et al. (2005). According to Metz, a power plant with a CCS system can still lose the equivalent of 10 to $20 \%$ of $\mathrm{CO}_{2}$ stack emissions to the atmosphere. 
The capture, compression, and pipelining of $\mathrm{CO}_{2}$ for sequestration would require 24 to $40 \%$ more energy from a coal power plant than that required by an equivalent plant without CCS. A combinedcycle natural gas power plant with CCS would require 11 to $22 \%$ more energy than that required by an equivalent plant without CCS. Lowend values from these ranges provided by Metz are used in the emissions computations herein, reflecting likely technological improvements over time.

\subsection{Results-Black Pellet bury-versus-burn comparisons}

Table 1 shows the net emissions results for the Phase 1 and Phase 2 bury-versus-burn comparisons before the advent of CCS. Table 2 shows the results of the Phase 3 and Phase 4 bury-versus-burn comparisons after the introduction of CCS in terms of both their comparative net emissions effects and their comparative requirements for geologic sequestration.

\subsubsection{Phase 1 results: OSB plus coal power generation versus burning the Black Pellets for power}

Assuming that coal and Black Pellets have substantially the same carbon contents and heating values, the two alternatives - burning the pellets for power or depositing them in the sea and continuing to burn the coal-would result in approximately the same net direct emissions for a given amount of power generated. However, the OSB case (Table 1, column B) would have two supply chains (those for coal and Black Pellets) versus the one supply chain (that for the Black Pellets) required when burning the pellets for power (column A). Due to this difference in supply chains, it is a robust conclusion that when the pellets and coal have substantially the same characteristics, it is better from both cost and emissions standpoints that the pellets be substituted for coal in power plants rather than be deposited in the sea for their negative emissions value. Introducing CCS in the power plant would equally affect burning the coal or pellets for power and, therefore, does not change this conclusion.

\subsubsection{Phase 2 results: OSB plus natural gas power generation versus burning the Black Pellets for power before CCS}

For 1 tonne of Black Pellets, the combination of OSB (1.91 tonnes of $\mathrm{CO}_{2 \mathrm{e}}$ negative emissions) with substitute power from natural gas (0.91 tonnes of $\mathrm{CO}_{2 \mathrm{e}}$ positive emissions) would result in 1.00 tonne of $\mathrm{CO}_{2 \mathrm{e}}$ direct negative emissions (Table 1 , column C). For comparison, net-zero emissions would result if the pellets were burned for power before supply chain considerations. However, the extra supply chain to obtain the natural gas reduces the advantage of the OSB scenario compared to the baseline scenario of using the pellets for power.

Taking supply chain effects into account, 0.34 tonnes of $\mathrm{CO}_{2 \mathrm{e}}$ net negative emissions per tonne of pellets would result from using the pellets for OSB with substitute power from natural gas (Table 1, column C) versus the net positive emissions of 39 tonnes of $\mathrm{CO}_{2 \mathrm{e}}$ from the scenario in which the pellets are used for power (column A). Therefore, a net negative emissions advantage of 0.73 tonnes $\mathrm{CO}_{2 \mathrm{e}}$ per tonne of pellets is obtained for the OSB scenario over the scenario in which the pellets are used for power generation $[-0.73=-0.34-(+0.39)]$. 


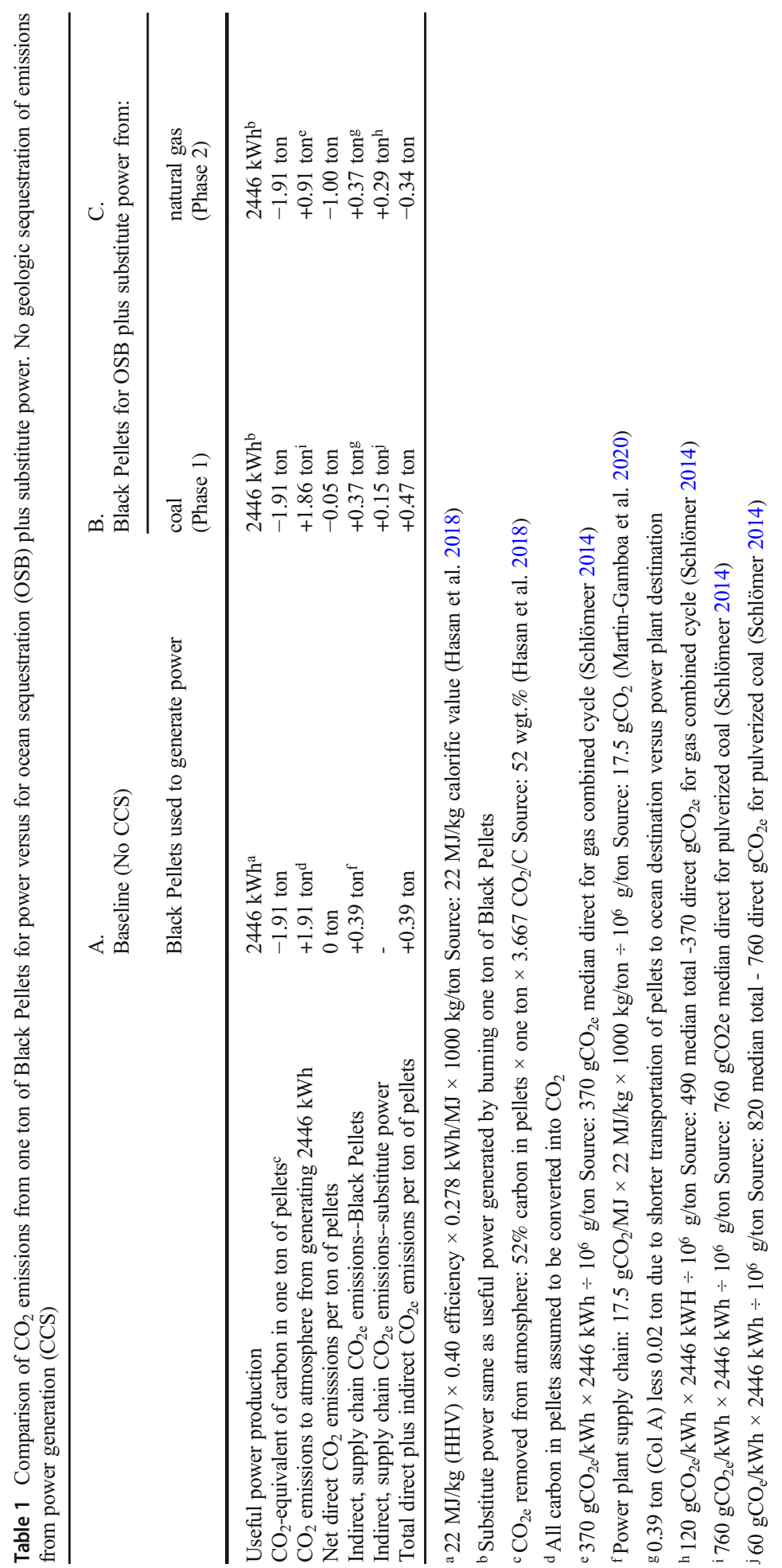




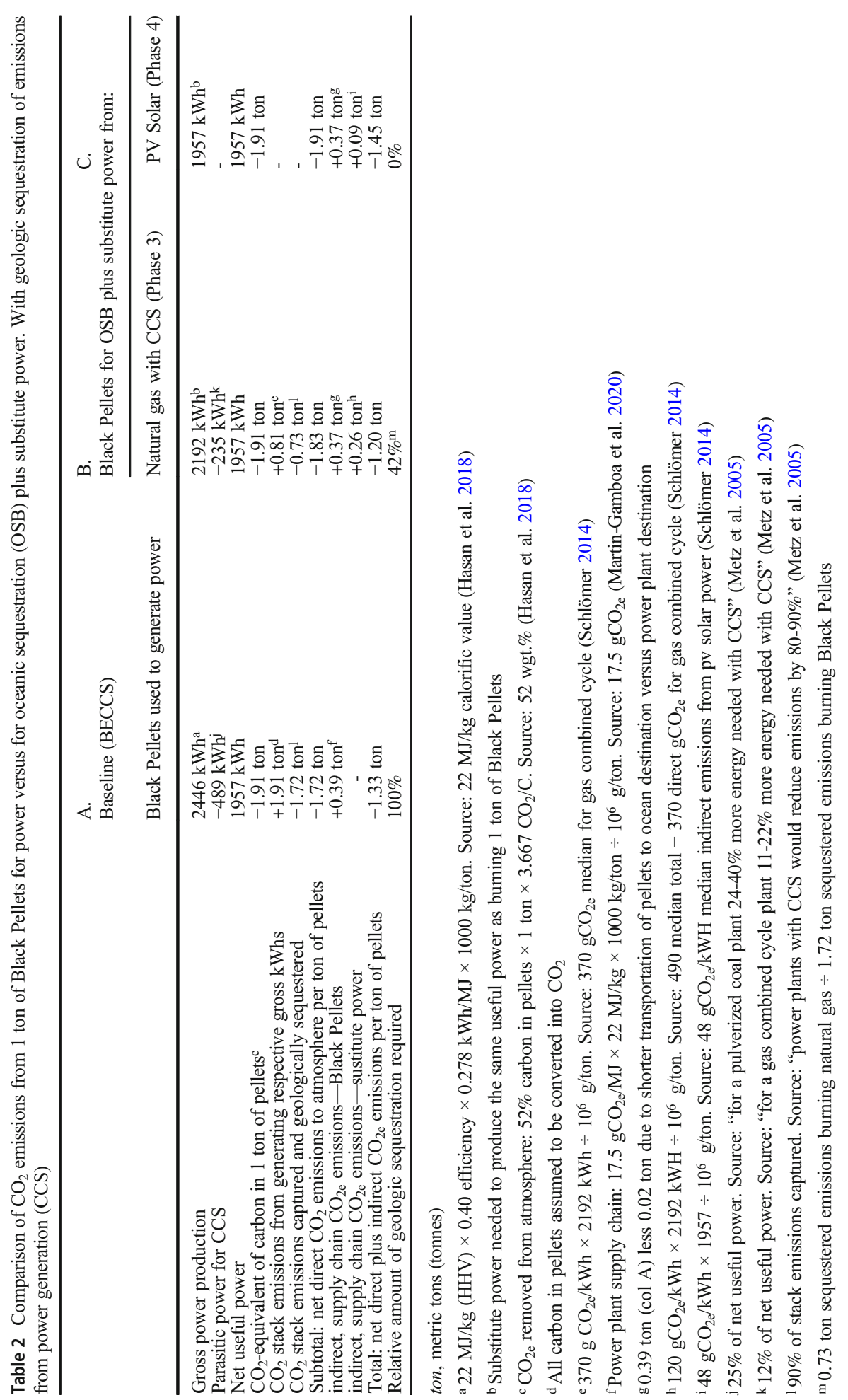




\subsubsection{Phase 3 results: OSB plus natural gas power generation with CCS versus Black Pellet BECCS}

Table 2, column A shows the baseline scenario in which the Black Pellets are burned in a power plant with CCS (BECCS). Table 2, column B shows the scenario in which the Black Pellets are deposited in the sea and the substitute power is generated by burning natural gas coupled with CCS.

A comparison of columns A and B in Table 2 shows that with CCS, for the same amount of useful electricity produced, a difference of 0.13 tonnes $\mathrm{CO}_{2 \mathrm{e}}$ per tonne of pellets more negative emissions is obtained in favor of using the pellets for power versus using them for OSB [+0.13 $=-1.20-(-1.33)$ ]. However, as shown in Table 2, column B, the major manifestation of OSB plus natural gas with CCS versus the use of Black Pellets for BECCS is that much less geologic sequestration is needed for OSB plus natural gas - about $58 \%$ less than that required for Black Pellet BECCS. This traces to the $53 \%$ less $\mathrm{CO}_{2}$ emissions from natural gas power than the emissions generated by burning the Black Pellets for the same amount of power. Adding to this is the circular effect in which the less parasitic electricity needed to capture the lower stack emissions from burning natural gas results in less emissions from generating this parasitic electricity.

\subsubsection{Phase 4 results: OSB plus carbon-free power generation versus Black Pellet BECCS}

When carbon-free energy sources can supply the energy to generate the substitute power needed with OSB, there is no need for geologic sequestration to achieve negative emissions, whereas the alternative baseline scenario to produce the same power, BECCS, involves geologic sequestration. Thus, the principal benefit of OSB in a future where carbon-free power generating sources are readily available would be the elimination of the need for geologic sequestration compared to using Black Pellets for BECCS. From the standpoint of net emissions, a comparison of columns $\mathrm{A}$ and $\mathrm{C}$ in Table 2 also shows that OSB plus carbonfree substitute energy as photovoltaic solar offers some negative emissions benefit, 0.12 tonnes $\mathrm{CO}_{2 \mathrm{e}}$ per tonne of pellets, versus using the same pellets for BECCS $[-0.12=-1.45-(-1.33)]$.

\subsection{Summary: dependence of OSB net emissions and geologic sequestration results on the form of substitute energy with and without CCS}

Table 3 is a summary of the foregoing results. Row 1, columns $\mathrm{C}$ through $\mathrm{F}$ show, over future phases of decarbonization, how OSB life cycle net emissions depend on the form of substitute energy for generating power without and then with CCS. Row 2 shows the relative net emissions advantage or disadvantage of OSB compared to baseline scenarios shown in columns $\mathrm{A}$ and $\mathrm{B}$ of using the Black Pellets for power. Row 3 shows the relative amounts of geologic sequestration required with using Black Pellets for OSB versus the baseline BECCS scenario.

Key results from Table 3 are: (a) with substitute energy from natural gas, before CCS, using Black Pellets for OSB would be advantageous by removing 0.73 tonnes of $\mathrm{CO}_{2}$ from the atmosphere per tonne of pellets relative to burning the pellets for power; (b) with substitute energy from natural gas and with CCS, using the pellets for OSB would be disadvantageous in producing 0.13 tonnes $\mathrm{CO}_{2}$ less negative emissions per tonne of pellets but would be advantageous by requiring $58 \%$ less geologic sequestration relative to burning the pellets in 


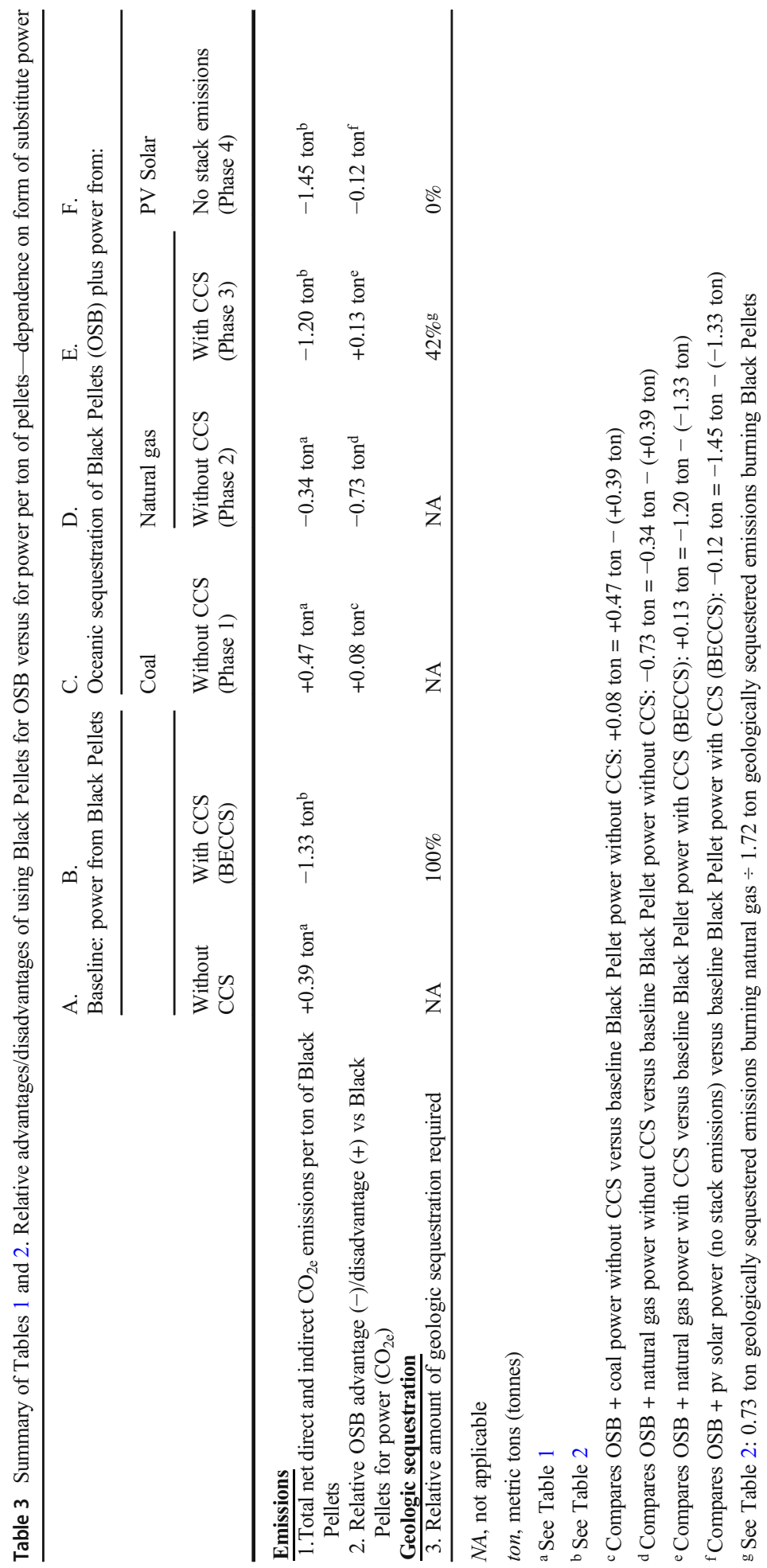


a BECCS configuration; and (c) with substitute energy from photovoltaic solar, OSB would be advantageous both by producing 0.12 tonnes $\mathrm{CO}_{2}$ more negative emissions and eliminating completely the need for geologic sequestration relative to burning the pellets in a BECCS configuration.

\section{Discussion}

\subsection{Antecedents and scientific foundations of OSB}

Metzger and Benford (2001) proposed depositing vegetation biomass in the form of bales of excess crop residues with weights attached in the ocean as a way of avoiding the $\mathrm{CO}_{2}$ that would otherwise enter the atmosphere if the vegetation was allowed to decay. They cited studies, e.g., Hoffert et al. (1980), that indicate $\mathrm{CO}_{2}$ originating on the sea floor several thousand meters deep, such as that from vegetation decay, would exhibit vertical transport measured in millennia, and if this vegetation were covered by ocean sediments, vertical transport could be indefinite.

Keith (2001) challenged Metzger and Benford saying that instead of wasting the energy value locked up in the vegetation biomass by depositing it in the ocean, it would be better to burn the vegetation and produce (almost) net-zero emission power. Keith (2001) essentially argued that burning fossil fuels for power to substitute for the sacrificed energy of vegetation deposited in the sea would produce the same net-zero emissions but would be more costly than burning the vegetation for power, i.e. due to the cost of furnishing the fossil fuels.

Metzger and Benford (2001) responded saying that Keith's (2001) "argument only would be true if the carbon per unit of primary energy through combustion (C/E), was the same for all organic fuels. In fact this is not nearly so." Metzger et al. (2002) went on to provide the scientific explanation through chemistry and thermodynamics that because natural gas has a much lower carbon-to-energy production ratio, it produces about half as much atmospheric emissions in a power plant compared to biomass fuel for an equivalent amount of power production. "This strongly suggests that rather than burning crop residue for power generation a combination of crop residue sequestration and power generation from lower carbon emission sources is a wiser optimum use of crop residues." Metzger et al. (2002) continued saying that Keith (2001) “... assigns a dollar cost to the two methods, rather than following the tradeoff between carbon and power."

In a final response, Keith and Rhodes (2002) conceded that sequestering vegetation biomass and replacing its sacrificed energy with lower-carbon sources such as natural gas would produce lower emissions than the zero net-emissions resulting from burning the vegetation; however, Keith and Rhodes maintained that "In the real world the costs of managing carbon do matter and the choice between these and other options will be determined strongly by economics."

Strand and Benford (2009) extended Metzger and Benford (2001). They provided cost estimates and emissions benefits of depositing in the ocean bales of excess agricultural wastes wrapped in plastic and ballasted with rocks.

The concept of OSB presented in this paper emerged from the realization that depositing Black Pellets in the ocean would offer the prospect of resolving the obvious impracticalities present in Strand and Benford (2009), namely, Black Pellets would not require a wrapper; the 
pellets would sink on their own, not requiring ballasting; and the form of vegetation biomass as Black Pellets would not be subject to the same microbial degradation as raw vegetation. Significantly, Strand and Benford's idea just pertains to a limited form of vegetation feedstocks - excess raw crop residues - whereas the oceanic deposition of Black Pellets is much more general, allowing for the thermochemical transformation of a wide variety of vegetation feedstocks, especially woody biomass.

\subsection{Reconciliation of economics versus energy efficiency perspectives for making Black Pellet bury-versus-burn decisions}

The exchanges between Metzger et al. and Keith and Rhodes constituted a debate over whether costs or emissions per unit of energy produced should be the critical factor in vegetation biomass bury-versus-burn decisions. Keith and Rhodes argued that because cost was the dominant consideration, the burning of vegetation for power was favored, even though it has less negative emissions benefit than sequestering the vegetation biomass in the sea and substituting energy from natural gas. However, Keith and Rhodes' approach to cost comparisons was incomplete which could lead to wrong conclusions.

Just comparing in isolation the cost of burning vegetation for power versus the cost of burying the vegetation and substituting energy overlooks that the use of vegetation biomass would be but one of a portfolio NETs that would be needed to mitigate climate change.

Finding the most economic (lowest cost, least resource-demanding) mix of NETs becomes a portfolio optimization problem that is constrained by the need to not only meet the 2100 goals of the Paris Agreement and beyond but also by the need to meet given global energy demands. In a portfolio of NETs, an increase in the quantity of negative emissions from any of the NET alternatives - say switching from using Black Pellets for energy to OSB with lower-carbon substitute energy-would have the effect of reducing the need for negative emissions from the most costly NET in the portfolio.

Due to its large need for power and other resources, among the most discussed NETs, DACCS appears to be the most costly, capital-intensive, resource-demanding NET on the horizon. Assuming so, optimization models would show that an increase in negative emissions from Black Pellets for OSB versus for power would result in a commensurate reduction in the need for negative emissions from DACCS. Thus, the economic value of using Black Pellets for OSB would be to reduce the use of DACCS resulting in a less costly, less resource-demanding pathway to meeting the 2100 Paris Agreement goals than using the pellets for power generation.

\subsection{Beyond 2100}

The National Academies of Sciences, Engineering, and Medicine (2019, pg. 23) report forecasts that beyond 2100, in a carbon-free power generating future, NETs still would be needed for an indefinite time. In such a future where low-cost carbon-free energy is readily available, OSB would provide negative emissions and geologic sequestration benefits compared to using Black Pellets for power. Assuming that OSB would produce negative emissions at less cost than that from DACCS, depositing Black Pellets in the sea would reduce the need for DACCS. In such a future, the mindset regarding the use of vegetation biomass to mitigate 
climate change would be as a direct source of negative emissions rather than, as it has generally been viewed heretofore, as a source of (almost) net-zero emissions energy.

Alternatively, in circumstances where the availability of low-cost carbon-free power is limited, it might be superior to use Black Pellets for BECCS where BECCS and DACCS facilities are coupled, the BECCS plant producing energy for, and sharing the geologic sequestration infrastructure with, the DACCS plant.

The potential benefit of OSB displacing a need for the more costly and resource-demanding DACCS does not mean that OSB must be concurrent with DACCS. The amount of DACCS needed to meet the Paris Agreement goals toward the end of century will depend on the amount of atmospheric $\mathrm{CO}_{2}$ that accumulates until then. A slow start in reducing atmospheric $\mathrm{CO}_{2}$ would cause damaging overshoot in global temperatures and the sooner we get started with reducing atmospheric $\mathrm{CO}_{2}$ the better. As it is based on fairly mature technologies (Negi et al. 2020), oceanic deposition of biocoal as Black Pellets may be a NET relatively ready-togo. A fast start with OSB would reduce the eventual amount of negative emissions needed toward the end of the century, thereby lessening the eventual need for DACCS.

\subsection{Logistics_optimal temporal and spatial deployment of Black Pellets}

\subsubsection{Temporal deployment of Black Pellets}

The generalized path to meeting the Paris Agreement goals of 2100 and meeting the world's demand for power assumed in this paper can be characterized as the global evolution of power generation decarbonization in different phases: (1) starting with coal, (2) ramping up with carbon-free sources through a transition period in which natural gas makes up for a shortfall in the availability of carbon-free sources, (3) the mid-century large-scale introduction of CCS, and (4) ultimately reaching entirely carbon-free power generation. The results in Table 3 lead to the following conclusions about the optimal use of Black Pellets in these four phases of global power migration to an entirely carbon-free power generating future:

- Phase 1: Coal power generation. Where power is generated from coal, it would be better to use Black Pellets as a coal substitute rather than OSB. Compared to using the pellets for power, OSB would add the cost of an extra supply chain without net emissions benefits.

- Phase 2: Natural gas power generation before CCS. Where low-leakage natural gas is available to generate power, it would be better to use Black Pellets for OSB than to use them to displace natural gas power generation. Although adding the cost of natural gas, OSB plus natural gas power would mean less $\mathrm{CO}_{2}$ in the atmosphere and, thereby, would reduce the future need for more costly NETs such as DACCS.

- Phase 3: Natural gas power generation with CCS. Where natural gas is available for power generation and can be coupled with CCS, there would be advantages and disadvantages to using Black Pellets for OSB rather than for power generation with CCS (BECCS). OSB plus natural gas with CCS may produce somewhat less negative emissions; however, using the pellets for OSB would mean approximately $58 \%$ less need for geologic sequestration compared to BECCS.

- Phase 4: Power production from carbon-free sources. Where carbon-free sources of power are readily available, Black Pellets should be used for OSB rather than to displace carbonfree power generation. Both a relative negative emissions benefit and an elimination of the 
need for geologic sequestration would result from OSB compared to using the pellets for BECCS.

In the foregoing conclusions, the availability of natural gas in the transition from coal to an entirely carbon-free power generating future should not be taken as a prediction of this paper. There is increasing awareness of significant harmful methane leakage in many natural gas supply chains, but where OSB is examined in this paper with natural gas as a substitute energy source, it is just illustrative of the results for natural gas from sources that meet stringent leakage controls, if available. This paper is in the spirit of the National Academies of Sciences, Engineering, and Medicine (2019, pg. 2) study, presenting what needs to be done to meet the Paris Agreement goal of controlling atmospheric $\mathrm{CO}_{2}$. From cost and technological standpoints, fixing natural gas supply chains is considered low-hanging fruit in mitigating climate change (IEA 2017) and it would be inconsistent to contemplate a future with BECCS and DACCS and not presume that low-leakage natural gas would be public policy.

Two key conclusions emerge from the bury-versus-burn analyses described in "Section 3.3":

- To the extent that OSB is used, it would result in a commensurate decrease in the worldwide need for geologic sequestration both from replacing BECCS with natural gas CCS and reducing the ultimate use of Direct Air Capture which requires CCS, and

- The faster humankind can achieve an entirely carbon-free power generating future, the larger would be the benefits from OSB.

\subsubsection{Spatial deployment of Black Pellets}

The foregoing principles of the optimal deployment of Black Pellets represent a generalized decarbonization evolution as applied to the world as a whole. However, viewing things spatially, there will be differences between countries concerning their decarbonization progress that would affect their individual decisions as to using Black Pellets for OSB or power.

The choice of how best to use Black Pellets - for energy or oceanic deposition - will depend on specific circumstances and that can change over time. For example, a country might abandon its coal dependence in favor of importing LNG, thereby switching the use of its pellets from being co-fired with coal for power generation to OSB. If circumstances warrant, the Black Pellets used for energy applications could readily be redirected to oceanic deposition or vice versa. From this emerges a key point: OSB is a negative emissions option that would provide a needed flexibility in meeting the 2100 Paris Agreement goals and beyond. The availability of OSB as an option would reduce investment risks and would add a degree of freedom in optimizing the global system for using vegetation biomass to mitigate climate change.

However, if each country acted independently, it could be witnessed that coal-equivalent biocoal was being dumped in the sea by some countries while elsewhere on the planet, coal was still being mined to generate power. In short, if each country on their own used the logistics principles described in "Section 4.4.1," it would lead to a globally suboptimal result. The global optimal usage of vegetation biomass to mitigate climate change would require international cooperation. 


\subsection{Governance}

Ideally, instead of each country deciding on the allocation of its own Black Pellets for OSB, the pellets would be regarded as a dual-purpose commodity for global allocation by an intergovernmental clearinghouse. Individual countries could meet their negative emissions commitments by contributing their pellets destined for OSB to the central body, irrespective of where on the planet the countries produced those supplies. The intergovernmental body would make allocation decisions - for oceanic deposition or burning for power-based on complex considerations regarding what then is best from a global climate change perspective. It might grant or sell pellets on a subsidized basis to, say, less developed counties as a coal substitute until when and if such countries could catch up with the rest of the world.

Envisioned herein is an international convention created to control the use of OSB. An intergovernmental body would be the permitting authority for all OSB activities. All dumping proposals would be examined and monitored on an ongoing basis to assure that the pellets meet established standards as to sustainable feedstock sourcing and chemical and physical characteristics. Specific marine environments for deposition would need approval after environment-specific scientific studies were conducted. The governing body would issue credits based on the quantities and qualities of deposited pellets in approved areas.

The potential deployment of OSB would raise novel issues that are the concern of many existing international laws, particularly:

- The UN Framework Convention on Climate Change (UNFCCC)

- The Paris Agreement

- The United Nations Convention on the Law of the Sea (UNCLOS)

- The Convention on Biodiversity (CBD)

Substantive discussion of OSB herein with respect to these laws would be premature. With this paper's objective being to propose research to answer threshold viability questions concerning OSB, immediately relevant to this objective are the London Convention and the London Protocol (LC/LP). As discussed in "Section 4.7," because OSB is a technology that involves dumping materials in the sea, the provisions of LC/LP directly pertain to the types of research on OSB and their staging that would be permissible.

\subsection{Oceanic environmental safety and sequestration persistence of OSB}

Here, unique aspects of Black Pellets are discussed regarding their chemical and physical properties which suggest that OSB offers the prospect of environmentally satisfactory longterm sequestration of atmospheric $\mathrm{CO}_{2}$. Different marine environment candidates for OSB are discussed in terms of their potential capacities to sequester Black Pellet material.

\subsubsection{Chemical properties of Black Pellets and their oceanic environmental implications}

Black Pellets show resistance to decay in terrestrial environments. Under torrefaction conditions, the hemicellulose component of vegetation decomposes to a recalcitrant form. The lignin component, a highly recalcitrant substance, increases as a percentage of the torrefied mass but remains largely unchanged chemically and plasticizes to become the key binding material 
during the pelletization process (Negi et al. 2020). It is a conjecture subject to research that Black Pellets as terrestrial material would be no more subject to microbial decay in the relatively cold, oxygen-poor deep sea as it is on land.

The rate of mixing of dense deep-sea waters with ocean-surface waters means that $\mathrm{CO}_{2}$ released from deep horizons is extremely slow. To the extent that remineralization of Black Pellet material into $\mathrm{CO}_{2}$ on the deep-sea floor occurs, models and observations indicate that venting of the $\mathrm{CO}_{2}$ to the atmosphere would be measured in centuries or millennia (Caldeira et al. 2005; Hoffert et al. 1980), the time generally increasing with depth. Deposition depth, rather than the less-certain rate of remineralization, is the key variable ito assure extremely long sequestration persistence through OSB.

The closest natural material to torrefied Black Pellets is lower-ranked coal but unlike some coals, Black Pellets made from raw vegetation should generally have less potential for containing leachates of concern such as heavy metals and sulfur. Feedstock selection and treatment methods are available to control the levels of harmful chemicals. Specific chemistry standards including for trace elements and nutrients would be imposed for Black Pellets intended for oceanic deposition just as chemistry standards are now specified for solid biofuels for use in energy applications.

\subsubsection{Physical properties of Black Pellets and their oceanic environmental implications}

Black Pellets are densified today to meet durability and safety requirements for industrial handing and transportation to overseas power plants. Their durability can be a matter of densification research and design with the objective of the pellets maintaining their integrity while sinking to the ocean floor.

Depositional control of the pellets would be a function of their rate of descent. The speed of descent of the Black Pellets to the sea floor can be influenced by their design, as this speed is a function of the pellet's size, shape, and specific gravity.

With months-long immersion in water, torrefied Black Pellets exhibit a mechanical breakdown into small particles having the absolute density and negative buoyancy of the original pellets and which form deposits with mud-like consistency (Thrän et al. 2016; Kymäläinen 2015). Such material mixing with seabed sediments or forming self-sealing deposits could suppress respiration effects but have the potential to envelope seabed lifeforms. The degree of concern over seabed disturbances depends on the thickness and areal extent of the deposited material which leads to the question of the scale of the deposits relative to the capacities of different ocean environments.

\subsubsection{Oceanic capacity for OSB}

Many IAM scenarios that meet the 2100 goals of Paris Agreement rely on $\mathrm{CO}_{2}$ removal and sequestration through all NETs starting in the 2030's, ramping up to about $10 \mathrm{GtCO}_{2}$ per year in the 2050's and reaching 20 Gt per year globally by the end of the century (National Academies of Sciences, Engineering, and Medicine 2019). Estimates of the cumulative need for NETs to meet the Paris Agreement goals vary widely, from 100 to as much as $1,000 \mathrm{GtCO}_{2}$ ( $1 \mathrm{GtCO}_{2}-1$ billion, $10^{9}$, metric tons of $\mathrm{CO}_{2}$ ) by 2100 (IPCC 2018). Thereafter, there would be a need for large-scale negative emissions over an indefinite period.

For pellets containing 1.54 tonnes $\mathrm{CO}_{2 \mathrm{e}}$ per tonne of pellets (see "Section 2.4"), one $\mathrm{GtCO}_{2 \mathrm{e}}$ would be sequestered by depositing approximately 649.4 million tonnes of pellets in the ocean. With a 
specific gravity of approximately 1.2 (Peng 2012), a tonne of Black Pellets would occupy $0.833 \mathrm{~m}^{3}$ on an absolute density basis (not bulk density). Therefore, each $\mathrm{GtCO}_{2 \mathrm{e}}$ would be contained in 541.0 million $\mathrm{m}^{3}$ of pellets in the sea, volumetrically equal to a cube $814.8 \mathrm{~m}$ on edge.

Rivers of the world deliver about $18 \mathrm{Gt}$ of sediments to the global ocean per year including embedded particulate terrestrial vegetation materials (Milliman and Farnsworth 2013). It is likely that the shelf sediment deposits of major rivers have capacity to embed meaningful amounts of Black Pellet material for indefinitely long sequestration, although the amounts and their fate in these environments would require much study.

The flat areas of mid-ocean abyssal plains are approximately 100 million $\mathrm{km}^{3}$ in extent, or approximately $28 \%$ of the global sea floor (Voelker 2016). Ranging from 3,500 to $6,000 \mathrm{~m}$ below the sea surface, they are relatively devoid of benthic biota reflecting the lower detritus flux and laterally transported terrestrial organic materials as nutrients compared to the ocean's continental margins. The equivalent of a billion tonnes of $\mathrm{CO}_{2}$ as Black Pellet material spread as a $1 \mathrm{~cm}$ thick layer deposited on abyssal plains would cover an area of 54,094 $\mathrm{km}^{3}$, approximately 5 ten-thousandths of the flat areas of the world's abyssal plains. Studies may show that an area thus disturbed may exhibit minor transient effects and may be reusable for further deposition in intervals of a given number of years.

The impact of OSB on the ocean's biota habitats and the persistence of sequestration of the Black Pellet material would be a function of its seafloor areal coverage and deposition thickness. Depositing the material in thick layers in depressions would not only reduce the areal extent of its seafloor disturbance but also suppress remineralization of the material in the lower layers.

As defined and mapped by Harris et al. (2014), there are many major seafloor depressions worldwide such as 57 trenches and 167 troughs. V-shaped subduction zone trenches near continental margins extend from seabed surfaces at 6,000 $\mathrm{m}$ deep to more than another 4,000 $\mathrm{m}$ deep. They are typically narrow — up to $100 \mathrm{~km}$ wide - and can extend more than $5,000 \mathrm{~km}$ long. At the bottom of some trenches, considerable microbial activity has been found feeding on trapped organic material runoff from nearby land and detritus from productive coastal ocean areas (Glud et al. 2013). Perhaps more promising for OSB from the standpoints of depositional control and sparser biotic activity are the geologically diverse flat-bottomed abyssal plain troughs at depths 4,000 to $5,000 \mathrm{~m}$ below the ocean surface.

The volumetric capacity of the world's deep ocean trenches and troughs to store $\mathrm{CO}_{2}$ is vast. By way of illustration, in an analysis of the capacities of very deep ocean trenches to store $\mathrm{CO}_{2}$ as a liquid, the calculations of Goldthorp (2017) indicated that $1,000 \mathrm{GtCO}_{2}$ - the extreme estimated cumulative need from all NETs through 2100 - could be contained as liquid $\mathrm{CO}_{2}$ in just $5 \%$ of the volume of a single trench, the Sunda, and that other trenches exist with similar capacities. Moreover, at depths where liquid $\mathrm{CO}_{2}$ would be compressed to a density equal to that of Black Pellet material, for a given volume, Black Pellet material as "concentrated" $\mathrm{CO}_{2 \mathrm{e}}$ would sequester approximately twice the amount of $\mathrm{CO}_{2 \mathrm{e}}$ that would be sequestered if in the form of liquid $\mathrm{CO}_{2}\left(\mathrm{CO}_{2 \mathrm{e}}: \mathrm{CO}_{2}=1.91: 1\right.$ see "Section 2.2").

\subsection{Social and legal barriers to deployment}

Intolerances to sacrifice loom large as deployment barriers to climate change solutions that appear to threaten peoples' economic well-being or ways of life. Where NETs involving the geologic sequestration of $\mathrm{CO}_{2}$ would overlap with population concentrations, people have shown concern about infrastructure intrusions associated with $\mathrm{CO}_{2}$ transportation and about real and imagined threats to their health and safety from geologic sequestration including 
seismic and leakage possibilities. Social acceptance has been deemed to be a significant barrier to the scale of deployment of BECCS that is considered necessary in many IAM scenarios to reach the goals of the Paris Agreement (Vaughan and Gough 2016).

The opportunities and their potential burdens associated with the various terrestrial NETs do not uniformly occur around the globe. Experience has shown that uneven terrestrial burdens can give rise to feelings of disproportionate sacrifices and antagonism among classes of people and among countries. Using the global ocean as "common ground" under joint governance should foster feelings of equity and cooperation. Nonetheless, surveys have consistently found more opposition to ocean-based versus terrestrial NETs (Bertram and Merk 2020; Cox et al. 2021). With much of the ocean still being a mystery, oceanic solutions to climate change are considered high risk with potential for unintended consequences. A strong aversion to "tampering with nature" leads many to feel we should leave the ocean alone.

Sober analysis, however, recognizes that humankind "has already been conducting a global intervention [affecting the ocean] through the rapid and sustained release of anthropogenic $\mathrm{CO}_{2}$ " (GESAMP 2019). Tipping point scenarios cannot be dismissed. To save the ocean and the rest of the Earth from catastrophic change, it may be necessary to look to the ocean as part of the solutions.

A need has been recognized for contingency planning to develop and compare oceanic climate change solutions. The Convention on the Prevention of Marine Pollution by Dumping Wastes and Other Matters (London Convention 1972) and the London Protocol (LC/LP) spell out what types of research on and deployment of those ocean-based solutions might be allowed based on the precautionary principle. To be consistent with the intent of LC/LP, approval of OSB deployment would require it to be deemed "dumping of uncontaminated organic material of natural origin, subject to satisfactory assessment." Nonetheless, "legitimate scientific research," especially laboratory research, is accepted as being appropriate.

\subsection{Comparison of OSB to other ocean-based NETs}

GESAMP (2019) was a major study undertaken to understand the potential environmental, social, and economic impacts of different ocean-based approaches to control climate change and to provide advice to the London Protocol Parties to assist them in identifying those approaches that might be acceptable to pursue. This study identified from the literature $27 \mathrm{such}$ ocean-based approaches for preliminary evaluation and ranking, including the following NETs that, like OSB, would use the ocean to sequester terrestrially captured $\mathrm{CO}_{2}$ :

- Depositing crop wastes in the deep ocean

- Injection and dissolution of liquid $\mathrm{CO}_{2}$ in mid/deep ocean waters

- Placing liquid $\mathrm{CO}_{2}$ on or within the deep seabed

- Mineralization of $\mathrm{CO}_{2}$ in rocks below the seabed

Relative to the foregoing approaches, OSB offers the following prospective advantages:

- OSB avoids the problems that make the ocean sequestration of crop wastes of limited applicability and impractical (see "Section 4.1").

- Black Pellet material deposited in the deep ocean offers the possibility of extremely long sequestration persistence as a consequence of it being the sequential combination of slow remineralization of a recalcitrant substance on or in the seabed followed by vertical transport over millennia of any $\mathrm{CO}_{2}$ that might be produced. 
- With long-lasting sequestration in deep-ocean levels, OSB should avoid the ocean acidification issues associated with direct injection and dissolution of $\mathrm{CO}_{2}$ at shallower depths in the sea (Goldthorp 2017).

- OSB offers high sequestration efficacy, as Black Pellet material contains approximately twice the amount of $\mathrm{CO}_{2 \mathrm{e}}$ as the same volume of liquid $\mathrm{CO}_{2}$ on or in the deep seabed. Depositing Black pellet material would result in approximately half the volumetric intrusion in the ocean and seabed compared to an equivalent amount of $\mathrm{CO}_{2}$ sequestered in liquid form.

- The costs and energy requirements of sequestration through OSB should be relatively low.

- Black Pellets material, as a reduced form of a natural substance (vegetation) and without unnatural additives, has characteristic that arguably meet the intent of the LC/LP regarding the acceptance of materials for dumping in the ocean. OSB may be seen to involve less tampering with the ocean, have less potential for unintended consequences, and be more "natural" than other approaches, akin to the processes that created coal deposits.

It would appear that OSB offers a set of characteristics that, if confirmed by research and design, would rank OSB favorably against the other leading ocean-based NET concepts. Consequently, discourse on OSB is encouraged, and a program of initial laboratory research is suggested.

\subsection{Suggested Black Pellet laboratory testing and optimization for oceanic deposition}

The pelletization stage of the manufacture of Black Pellets has design variables — pellet size, shape, and density - that would be tuned to affect the speed and drift of the pellets in their descent to the sea floor. The durability of the pellets of different types would be tested under a range of high-pressure conditions, including those that were pelletized prior to torrefaction and steam explosion pellets which have shown greater resistance to mechanical breakdown with prolonged immersion in water (Kymäläinen 2015). Mechanisms and systems would be investigated for precision deposition including adapting existing ultra-deepwater drilling technologies to deliver Black Pellet material to the sea floor as slurries through vertical pipes. Earth system and integrated assessment models would be used to predict environmental, economic, and other societal impacts over numerous what-if scenarios. If these threshold design activities and laboratory experiments produce favorable results, LC/LP petitions would be made to investigate depositional methods, the effects on ocean chemistry, disturbances of lifeform habits and habitats, and Black Pellet degradation in actual marine environments.

\section{Conclusion-OSB in perspective}

OSB plus low-carbon substitute energy would be an alternative to BECCS. Subject to research and design, for the same vegetation feedstocks, OSB offers the prospect of more global negative emissions and/or less need for geologic sequestration than BECCS. The potential benefits of OSB would grow with increasing decarbonization of global power generation. In a future in which power is readily available from carbon-free sources, vegetation biomass would be valued through OSB as a direct source of negative emissions rather than as andirect source of negative emissions as a fuel for BECCS. 
Based on the same feedstocks, OSB and BECCS share the same uncertainty regarding how much sustainable vegetation biomass the world will be able to produce. To the extent that technology and agricultural and social practices evolve to furnish a supply of sustainable vegetation biomass while satisfying the world's need for crops, OSB offers the prospect of reducing our dependence on other NETs such as DACCS.

As it involves depositing material in the sea, OSB faces a high threshold for social acceptance; but it offers the prospects of less volumetric intrusion and less potential harm to the ocean and its biota than other ocean-based NETs. Laboratory research seems justified to advance OSB as a contingency if and when it becomes clear we cannot avoid turning to the ocean in the fight against climate change.

Availability of data and material Not applicable.

Code availability Not applicable.

Funding P. Orton was supported by the National Oceanic and Atmospheric Administration (NOAA) Regional Integrated Sciences and Assessments (RISA) program (Award NA10OAR4310212).

\section{Declarations}

Conflict of interest The authors declare no competing interests.

Open Access This article is licensed under a Creative Commons Attribution 4.0 International License, which permits use, sharing, adaptation, distribution and reproduction in any medium or format, as long as you give appropriate credit to the original author(s) and the source, provide a link to the Creative Commons licence, and indicate if changes were made. The images or other third party material in this article are included in the article's Creative Commons licence, unless indicated otherwise in a credit line to the material. If material is not included in the article's Creative Commons licence and your intended use is not permitted by statutory regulation or exceeds the permitted use, you will need to obtain permission directly from the copyright holder. To view a copy of this licence, visit http://creativecommons.org/licenses/by/4.0/.

\section{References}

Adams P, Shirley J, McManus M (2015) Comparative cradle-to-gate life cycle assessment of wood pellet production with torrefaction. Appl Energy 138:367-380. https/doi.org/10.1016/j.apenergy.2014.11.002

Batidzirai B, Junginger M, Klemm M, Schipfer F, Thrän D (2016) Chapter 5 biomass supply and trade opportunities of preprocessed biomass for power generation. In: Lamar P et al (eds) Developing the global bioeconomy. Academic Press, Cambridge MA, pp 91-114

Bergman P (2005) Combined torrefaction and pelletisation: the TOP process. Energy Research Centre of the Netherlands Report no. ECN-C-05-0073

Bertram C, Merk C (2020) Public perceptions of ocean-based carbon dioxide removal: the nature-engineering divide? Front Clim 2:594194. https://doi.org/10.3389/fclim.2020.594194

Caldeira K, Akai M, Brewer P et al (2005) Ocean storage. In: Metz B, Davidson O, Coninck H, Loos M, Meyer L (eds) Carbon dioxide capture and storage. IPCC, Cambridge University Press, Cambridge UK pp, pp 279311

Cox E, Boettcher M, Spence E, Bellamy R (2021) Casting a wider net on ocean nets. Front Clim 3:576294. https://doi.org/10.3389/fclim.2021.576294

GESAMP (2019) High level review of a wide range of proposed marine geoengineering techniques. Boyd, P.W. and Vivian, C. (eds.) IMO/FAO/UNESCO-IOC/UNIDO/WMO/IAEA/UN/UN Environment/UNDP/ISA Joint Group of Experts on the Scientific Aspects of Marine Environmental Protection. Rep. Stud. GESAMP No. 98 http://www.gesamp.org/publications/high-level-review-of-a-wide-range-of-proposedmarine-geoengineering-techniques 
Glud R et al (2013) High rates of microbial carbon turnover in sediments in the deepest oceanic trench on Earth. Nat Geosci 6:284-288. https://doi.org/10.1038/ngeo1773

Goldberg D (2019) The Earth needs multiple methods for removing CO2 from the air to avert worst of climate change. The Conversation 12/13/2019 https://theconversation.com/the-earth-needs-multiple-methods-forremoving-co2-from-the-air-to-avert-worst-of-climate-change-121479

Goldthorp S (2017) Potential for very deep ocean storage of $\mathrm{CO}_{2}$ without acidification: a discussion paper. Energy Procedia 114:5417-5429 https://www.sciencedirect.com/science/article/pii/S1876610217318878

Harris PT et al (2014) Geomorphology of the oceans. Mar Geol 352:4-24 https://www.researchgate.net/profile/ Peter_Harris14/publication/260031735_Geomorphology_of_the_oceans/links/5a717fb0aca272e425edaaec/ Geomorphology-of-the-oceans.pdf?origin=publication_detail

Hasan M, Haseli Y, Karadogan E (2018) Correlations to predict elemental compositions and heating value of torrefied biomass. Energies 11(9):2443. https://doi.org/10.3390/en11092443

Hoffert M, Callegari A, Hsieh C (1980) The role of deep sea heat storage in the secular response to climatic forcing. J Geophys Res 85(C11):6667-6679

IEA (2017) World energy outlook 2017. IEA, Paris https://www.iea.org/reports/world-energy-outlook-2017

IPCC (2018) Global warming of $1.5^{\circ} \mathrm{C}$. https://ipcc.ch/pdf/special-reports/sr15/sr15_spm_final.pdf

Keith DW (2001) Sinks, energy, crops and land use: coherent climate policy demands an integrated analysis of biomass an editorial comment. Clim Chang 49:1-10

Keith DW, Rhodes JS (2002) Bury, burn or both: a two-for-one deal on carbon and energy reply to R. A. Metzger, G. Benford, and M. I. Hoffert. Clim. Change 54: 375-377. 10.102/A:1016187420042

Kymäläinen M (2015) Moisture sorption properties and fungal degradation of torrefied wood. Dissertation Forestales 206 University of Helsinki

Martin-Gamboa M et al (2020) Life cycle assessment of biomass pellets: a review of methodological choices and results. Renew Sust Energ Rev 133:1-13. https://doi.org/10.1016/j.rser.2020.110278

McNamee P et al (2016) An assessment of the torrefaction of North American pine and life cycle greenhouse gas emissions. Energy Convers Manag 113:117-188. https://doi.org/10.1016/j.enconman.2016.01.006

Metz B, Davidson O, de Coninck H, Loos M, Meyer L (2005) IPCC special report on carbon dioxide capture and storage. Cambridge University Press, Cambridge New York, NY USA

Metzger R, Benford G (2001) Sequestering of atmospheric carbon through permanent disposal of crop residue. Clim Chang 49:11-19. https//doi.org/10.1023/A:1010765013104

Metzger R, Benford G, Hoffert MI (2002) To bury or to burn: optimum use of crop residues to reduce atmospheric $\mathrm{CO}_{2}$. Clim Chang 54:369-374. https://doi.org/10.1023/A1016136202309

Milliman J and Farnsworth K (2013) River discharge to the coastal ocean - a global synthesis. Cambridge University Press, MA, USA https://doi.org/10.1017/CBO9780511781247

National Academies of Sciences, Engineering, and Medicine (2019) Negative emissions technologies and reliable sequestration: a research agenda. The National Academies Press, Washington DC. https://doi.org/ $10.17226 / 25259$

Negi S et al (2020) Torrefaction: a sustainable method for transforming agri-wastes to high energy density solids (biocoal). Rev Environ Sci Biotechnol 19:463-488. https://doi.org/10.1007/s11157-020-09532-2

Peng J (2012) A study of torrefaction and densification for the production of high quality wood pellets. The University of British Columbia, Thesis

Schlömer S (2014) Mitigation of climate change, Annex III: technology-specific cost and performance parameters. In: Climate change 2014: fifth assessment report of the intergovernmental panel on climate change. Cambridge University Press, Cambridge United Kingdom and New York, NY, USA

Strand S, Benford G (2009) Ocean sequestration of crop residue carbon: recycling fossil fuel carbon back to deep sediments. Environ Sci Technol 43:1000-1007. https://doi.org/10.1021/es8015556

Thrän D et al (2016) Moving torrefaction towards market introduction-technical improvements and economicenvironmental assessment along the overall torrefaction supply chain through the SECTOR project. Biomass Bioenergy 89:184-200. https://doi.org/10.1016/j.biombioe.2016.03.004

Tisserant A, Cherubini F (2019) Potentials, limitations, co-benefits, and trade-offs of biochar applications to soils for climate change mitigation. Land 8:179. https://doi.org/10.3390/land8120179

Vaughan N, Gough C (2016) Expert assessment concludes negative emissions scenarios may not deliver. Environ Res Lett 11(9):095003. https://doi.org/10.1088/1748-9326/11/9/095003

Voelker D (2016) Abyssal plains. In: Harff J, Meschede M, Petersen S, Thiede J (eds) Encyclopedia of Marine Geosciences. Springer, Dordrecht. https://doi.org/10.1007/978-94-007-6238-1_211

Wild $\mathrm{M}$ et al (2016) Possible effects of torrefaction on biomass trade. IEA Bioenergy Task 40

Publisher's note Springer Nature remains neutral with regard to jurisdictional claims in published maps and institutional affiliations. 